\title{
Insulin and osteocalcin: further evidence for a mutual cross-talk
}

\author{
Francesco L. Bilotta $^{1} \cdot$ Biagio Arcidiacono $^{1} \cdot$ Sebastiano Messineo $^{1} \cdot$ Marta $_{\text {Greco }^{1}}$. \\ Eusebio Chiefari ${ }^{1} \cdot$ Domenico Britti $^{1} \cdot$ Tomoko Nakanishi $^{2} \cdot$ Daniela P. Foti $^{1}{ }^{1} \cdot$ \\ Antonio Brunetti ${ }^{1}{ }^{1}$
}

Received: 1 July 2017 / Accepted: 14 August 2017 / Published online: 2 September 2017

(C) The Author(s) 2017. This article is an open access publication

\begin{abstract}
Purpose In the last few years, bone has been recognized as an endocrine organ that modulates glucose metabolism by secretion of osteocalcin, an osteoblast-specific hormone, that influences fat deposition and blood sugar levels. To date, however, very few in vitro models have been developed to investigate, at the molecular levels, the relationship between glucose, insulin and osteocalcin. This study aims at covering this gap.

Methods We studied osteogenic differentiation, osteocalcin gene expression, and osteblast-mediated insulin secretion, using cultured MG-63 human osteoblast-like cells that underwent glucotoxicity and insulin resistance. In addition, we investigated whether a correlation existed between hyperglycemia and/or insulin resistance and total osteocalcin serum concentrations in patients.

Results While insulin and low glucose increased osteocalcin gene expression, disruption of insulin signaling in MG-63 osteoblasts and high glucose concentration in cell culture medium decreased osteocalcin gene transcription and reduced osteogenic differentiation. Concomitantly, insulin secretion was significantly impaired in rat INS- $1 \beta-$ cells treated with conditioned medium from insulin resistant MG-63 cells or cells exposed to high glucose
\end{abstract}

The original version of this article was revised due to a retrospective Open Access order.

Antonio Brunetti

brunetti@unicz.it

1 Department of Health Sciences, University "Magna Græcia” of Catanzaro, Viale Europa (Località Germaneto), 88100 Catanzaro, Italy

2 Laboratory of Molecular Genetics, The Institute of Medical Science, University of Tokyo, 108-8639 Tokyo, Japan concentrations. Also, chronic hyperglycemia, but not insulin resistance, inversely correlated with circulating osteocalcin levels in patients.

Conclusion Our results further support the existence of an endocrine axis between bone, where osteocalcin is produced, and pancreatic $\beta$-cells, and add new insights into the molecular details of this relationship. These findings may contribute to the understanding of osteocalcin regulation and its role in metabolism.

Keywords Bone $\cdot$ Osteocalcin $\cdot$ Insulin action $\cdot$ Type 2 diabetes

\section{Introduction}

The regulation of glucose metabolism in mammals is a complex physiological process based on the interplay of a variety of hormones and other extracellular signals acting on specific target tissues. Among the main hormones involved in this process, insulin plays a major role in promoting glucose uptake in muscle and adipose tissue, while it suppresses gluconeogenesis in the liver [1], thereby reducing postprandial glucose levels in the blood. Because of the fundamental importance of insulin within this context, the insulin receptor signaling pathway has been studied intensively through the past decades, with the identification, in recent years, of novel non-canonical insulin target tissues that appear to play important roles in whole body glucose homeostasis. In line with this finding, the existence of an insulin receptor signaling pathway has been defined recently in the bone, specifically in osteoblasts [2], leading to the conclusion that bone can be a target of insulin action and a major regulator of energy metabolism by favoring $\beta$ cell insulin secretion and peripheral insulin sensitivity 
through an intricate array of hormones and other factors acting locally and systemically [3, 4].

In particular, a key role in the regulation of glucose metabolism, at this level, is attributed to osteoblasts [5], which produce the osteoblast-specific protein, osteocalcin, the most abundant non-collagenous protein in the bone. Before being secreted into blood, osteocalcin is carboxylated on three glutamine residues (Bone Gla Protein) [6] through vitamin K-dependent mechanisms. The carboxylation of osteocalcin confers high affinity for bone matrix, whereas decarboxylation generates the formation and activation of the hormonal form of osteocalcin [7]. The evidence that osteocalcin may have an extraskeletal metabolic role beyond its effect on bone is supported by data from mice lacking osteocalcin, in which an increase in visceral fat followed by hyperglycemia and hypoinsulinemia was observed, together with a reduced $\beta$-cell mass and insulin content [8]. Besides promoting insulin secretion, osteocalcin increases peripheral insulin sensitivity $[9,10]$. Interestingly, in mice lacking either one copy of the insulin receptor gene in osteoblasts, or the osteocalcin gene, high fat diet (HFD) induced a more severe form of insulin resistance than wild-type mice did [11], whereas selective overexpression of the insulin receptor in osteoblasts protected from HFD-induced insulin resistance.

Based on the experimental findings so far available, the existence of a positive loop between osteocalcin and insulin is suggested, by which osteocalcin stimulates insulin secretion, while the release of osteocalcin is enhanced by insulin. In support of this view, patients with insulin resistance and abnormalities in glucose metabolism have low circulating osteocalcin levels, and may have consequences in their bone structure and function (e.g., higher risk of fractures) [12], thereby further strengthen the link between skeletal and glucose metabolism.

In the present study, we confirm and extend previous observations linking osteocalcin and glucose metabolism. Using in vitro models of insulin resistance, we provide data that can help to better understand the role of osteocalcin in the pathophysiology of insulin deficiency and the events leading to insulin-resistant states and metabolic disorders.

\section{Materials and methods}

\section{Cells}

MG-63 (ATCC CRL-1427) human osteosarcoma cells and the human embryonic kidney HEK-293 cell line [13] were cultured in Dulbecco's Modified Eagle's medium (DMEM) (Invitrogen) supplemented with $10 \%$ fetal bovine serum (FBS), $2 \mathrm{mM}$ glutamine, penicillin $(100 \mathrm{U} / \mathrm{mL})$, and streptomycin $(100 \mu \mathrm{g} / \mathrm{mL})$ in a humidified $5 \% \mathrm{CO}_{2}$ atmosphere at $37{ }^{\circ} \mathrm{C}$. INS-1 rat insulinoma cells [13] were cultured in RPMI-1640 medium (Sigma-Aldrich) supplemented with $10 \%$ FBS, $2 \mathrm{mM}$ glutamine, penicillin $(100 \mathrm{U} / \mathrm{mL})$, streptomycin $(100 \mu \mathrm{g} / \mathrm{mL}), 50 \mu \mathrm{M}$ beta-mercaptoethanol, and $100 \mathrm{mM}$ HEPES buffer (Sigma-Aldrich). The culture medium was replaced every 3 days.

\section{Osteogenic differentiation}

MG-63 cells were seeded at approximately 3000 cells $/ \mathrm{cm}^{2}$ in 24-well culture plates and maintained in an incubator at $37^{\circ} \mathrm{C}$ and $5 \% \quad \mathrm{CO}_{2}$. After $48 \mathrm{~h}$, the standard medium was replaced with osteogenic medium, consisting of DMEM with $10 \%$ FBS, $50 \mu \mathrm{g} / \mathrm{mL} 2 \mathrm{P}$-ascorbic acid, $100 \mathrm{nM}$ dexamethasone, $10 \mathrm{mM} \quad \beta$-Glycerophosphate disodium salthydrate, $2 \mathrm{mM}$ L-glutamine, $100 \mathrm{U} / \mathrm{ml}$ penicillin, $100 \mu \mathrm{g} / \mathrm{mL}$ streptomycin. The culture medium was changed every 3-4 days until 14 days of culture.

\section{Induction of insulin resistance}

Palmitic acid (Sigma-Aldrich) was first dissolved in ethanol at a concentration of $200 \mathrm{mM}$ and then diluted (1:20) with phosphate-buffered saline (PBS) 1X, plus $10 \%$ fatty acid free BSA (Sigma-Aldrich) at $65^{\circ} \mathrm{C}$ for $15 \mathrm{~min}$. Palmitate was added into cell culture medium at $200 \mu \mathrm{M}$ for 2 days to induce insulin resistance.

\section{Treatment with glucose and insulin}

Low, standard or high glucose concentrations $(2,5$, and 25 $\mathrm{mM}$, respectively) were added to glucose-free culture medium starting from $24 \mathrm{~h}$ after seeding (on day 1) and after each medium change during the time course experiments. To examine insulin signaling, cells were treated with $10 \mathrm{nM}$ Insulin (Sigma-Aldrich) [11].

\section{Culture-conditioned medium from MG-63 cells and insulin secretion}

Insulin resistant and non-insulin resistant MG-63 cells were cultured and differentiated for 14 days in osteogenic medium. Subsequently, the culture conditioned medium was collected and centrifuged for $10 \mathrm{~min}$ at $1500 \times g$ (to remove cells and cell debris in the solution) and then filtered and stored at $-80{ }^{\circ} \mathrm{C}$. INS- 1 cells were grown in RPMI-1640 at $80 \%$ confluence, and starved overnight in Hank's Balanced Salt Solution (HBSS) buffer, supplemented with standard 5 $\mathrm{mM}$ glucose. The following morning, cells were switched to fresh HBSS buffer and insulin secretion was measured at 3 and $15 \mathrm{mM}$ glucose, with and without the addition of conditioned medium from insulin resistant and non-insulin resistant MG-63 cells [14]. 


\section{Reporter assay}

For luciferase reporter assays, $2 \mu \mathrm{g}$ of pOC-Luc (luciferase gene with the human osteocalcin promoter) or $\mathrm{p} \Delta \mathrm{OC}$-Luc (luciferase gene without the osteocalcin promoter) [15], were transiently transfected into MG-63 and HEK-293 cells, using the LipofectAMINE 2000 reagent (Thermofisher), and luciferase activity was assayed $48 \mathrm{~h}$ later, using the dual-luciferase reporter assay system (Promega) [16]. The effects of different concentrations of glucose on the osteocalcin promoter were tested after $48 \mathrm{~h}$ of stimulation.

\section{Detection and quantification of mineralization}

Esperiments were performed as previously described [17]. MG-63 monolayers in 24-well plates $\left(2 \mathrm{~cm}^{2} /\right.$ well) were washed with PBS and fixed in $10 \%$ (v/v) formaldehyde. The monolayers were then washed with PBS prior to addition of $1 \mathrm{~mL}$ of $40 \mathrm{mM}$ Alizarin Red S (ARS, Sigma-Aldrich) per well. The plates were incubated for $20 \mathrm{~min}$. After aspiration of the unincorporated dye, the wells were washed five times with PBS while shaking for $5 \mathrm{~min}$. The plates were then stored at $-20{ }^{\circ} \mathrm{C}$ prior to dye extraction. Stained monolayers were visualized by phase microscopy using an inverted microscope (Leica). For quantification of staining, $500 \mu \mathrm{L} 10 \%$ (v/v) acetic acid was added to each well, and plates incubated at room temperature for $30 \mathrm{~min}$ with shaking. The monolayer was then scraped from the plate and transferred with $10 \%(\mathrm{v} / \mathrm{v})$ acetic acid to a $1.5-\mathrm{mL}$ microcentrifuge tube. The slurry was heated to exactly $85^{\circ} \mathrm{C}$ for $10 \mathrm{~min}$, and transferred to ice for $5 \mathrm{~min}$. The slurry was then centrifuged at $20.000 \mathrm{~g}$ for $15 \mathrm{~min}$ and $500 \mu \mathrm{L}$ of the supernatant was removed to a new $1.5-\mathrm{mL}$ microcentrifuge tube. Then, $150 \mu \mathrm{L}$ of $10 \%$ (v/v) ammonium hydroxide was added to neutralize the acid. Aliquots (100 $\mu \mathrm{L}$ ) of the supernatant were read in triplicate at $405 \mathrm{~nm}$ in 96-well format using opaque-walled, transparent-bottomed plates.

\section{Protein extract and western blot}

Cells were washed with PBS, harvested and the cell pellet resuspended in radioimmunoprecipitation assay buffer (50 $\mathrm{mM}$ Tris- $\mathrm{HCl}$, pH 7.4; $1 \%$ NP-40; $0.5 \%$ Na-deoxycholate; $0.1 \%$ SDS; $1 \mathrm{mM}$ EGTA; $1 \mathrm{mM}$ PMSF; $150 \mathrm{mM} \mathrm{NaCl} ; 1$ $\mathrm{mM}$ Na-orthovanadate; $10 \mathrm{mM} \mathrm{NaF}$; anti-proteases). Final protein concentrations in the extracts were determined using the colorimetric assay of Bradford. Total protein extracts were resolved on sodium dodecyl sulfate polyacrylamide gel electrophoresis and electrotrasferred onto a $0.2 \mu \mathrm{m}$ PVDF membrane (Merck-Millipore) [18]. The antibodies used for these studies were: anti-phospho-AKT Ser473 (Cell Signaling), anti-AKT (Santa Cruz Biotechnology), anti-phospho IRS-1 Tyr612 (Merck-Millipore) and antiIRS-1 (Abcam), anti-OCN (Merck-Millipore), anti- $\beta$-tubulin (Cell Signaling). The resulting immunocomplexes were visualized by enhanced chemiluminescence.

\section{RNA extraction and qRT-PCR analysis}

Total cellular RNA was extracted with Trizol (Invitrogen) [19] and subjected to DNase treatment (Ambion). Amounts were normalized against ribosomal RNA in each sample. cDNAs were synthesized from $2 \mu \mathrm{g}$ of total RNA using the RETROscript first strand synthesis kit (Ambion). A realtime thermocycler (Eppendorf Mastercycler ep realplex ES) was used to perform qRT-PCR. SYBR Green fluorescence was measured, and relative quantification was made against the RPS 9 cDNA used as an internal standard. Gene-specific primers for qRT-PCR (rat InsI for GACCCGCAAGTGCCACAA, rev TCCACAAGCCACGCTTCTG; human $O C N$ for TGACGAGTTGGCTGACCA, rev AGGGTGCCTGGAGAGGAG) were designed according to sequences from the GenBank database.

\section{Insulin assay}

Insulin levels were measured in cell culture medium using the rat insulin ELISA kit produced by Mercodia Co., Sweden, and an EIA plate reader with a $450 \mathrm{~nm}$ filter (Statfax 2100, USA) cells [14].

\section{Clinical data}

A total of 64 consecutive unrelated subjects with and without type 2 diabetes mellitus, attending the Operative Unit of Endocrinology (University "Magna Græcia", Catanzaro), were recruited in the study (Table 1). In affected individuals, diabetes was diagnosed according to the American Diabetes Association criteria based on fasting glucose levels (126 mg/dL) [20]. None of them were taking any hypoglycemic medications, and diabetes was controlled by diet only, both in new patients and in diabetic patients with glycated hemoglobin (HbA1c) below $7 \%$ $(53.0 \mathrm{mmol} / \mathrm{mol})$ at the previous visit. Reasons for exclusion included osteoporosis ( $T$ score $\leq-2.5)$ and conditions/ drug treatments known to influence bone homeostasis. In non-diabetic subjects, bone metabolism-related diseases such as hypothyroidism, hyperthyroidism, primary hyperparathyroidism and osteoporosis were excluded on clinical ground, together with the exclusion of drugs affecting bone mineral metabolism. In all subjects, blood was withdrawn for the contextual determination of serum glucose, insulin and $\mathrm{HbA} 1 \mathrm{c}$, while an aliquot was stored at $-80{ }^{\circ} \mathrm{C}$ for the subsequent analysis of total osteocalcin. Using the homeostatic model assessment for insulin resistance (HOMA-IR), 
Table 1 Demographic, anthropometric, clinical and biochemical features of selected subjects

\begin{tabular}{llll}
\hline Features & T2D $N=22$ & Control $N=42$ & $P$ \\
\hline Ethnicity & Caucasian & Caucasian & - \\
Female $(\mathrm{n})$, & $7(60.0)$ & $23(50.0)$ & 0.114 \\
Age $(\mathrm{yr})$ & $67(56-73)$ & $59(50-70)$ & 0.092 \\
BMI $\left(\mathrm{Kg} / \mathrm{m}^{2}\right)$ & $27.0(24.5-29.3)$ & $25.5(24.3-29.8)$ & 0.415 \\
FPG $(\mathrm{mg} / \mathrm{dL})$ & $158(117-184)$ & $94(86-101)$ & $<0.001$ \\
HbA1c $(\%)$ & $7.9(7.6-8.8)$ & $5.6(5.4-5.8)$ & $<0.001$ \\
HbA1c $(\mathrm{mmol} / \mathrm{mol})$ & $62.8(59.6-72.7)$ & $37.7(35.5-39.9)$ & $<0.001$ \\
HOMA-IR & $6.9(3.7-18.6)$ & $3.9(1.2-5.4)$ & $<0.001$ \\
Insulin $(\mathrm{mU} / \mathrm{L})$ & $18(11-44)$ & $15.5(6-23)$ & 0.038 \\
\hline
\end{tabular}

Data are medians (IQR), or $n(\%)$. Non-parametric Mann-Whitney test was used for distribution comparisons of quantitative variables. The two-tailed Fisher exact test was used for proportion comparisons between groups $B M I$ body mass index, $F P G$ fasting plasma glucose, HOMA-IR homeostatic model assessment method of insulin resistance

Significance level $P<0.05$

patients were classified as insulin sensitive (HOMA-IR < 1.6) or insulin resistant (HOMA-IR > 2.5). Blood glucose, insulin and HbA1c were measured by standard techniques with the instruments Cobas 6000 (Roche), Advia Centaur (Siemens) and HA8160 (Menarini), respectively. Imprecision data were as follows: serum glucose average intraassay $\mathrm{CV}=1.8 \%$, inter-assay $\mathrm{CV}=2.1 \%$; serum insulin average intra-assay $\mathrm{CV}=4.9 \%$, inter-assay $\mathrm{CV}=5.2 \%$; $\mathrm{HbA} 1 \mathrm{c}$ average intra-assay $\mathrm{CV}=0.9 \%$, inter-assay $\mathrm{CV}=$ $1.4 \%$. HOMA-IR was calculated by the formula: glucose $(\mathrm{mg} / \mathrm{dL}) \mathrm{x}$ insulin $(\mathrm{mU} / \mathrm{L}) / 405$. Total serum osteocalcin was measured by a one-step chemiluminescent immunoassay (Liaison, DiaSorin). Serum osteocalcin average intra-assay $\mathrm{CV}=4.9 \%$, inter-assay $\mathrm{CV}=6.7 \%$. The study was approved by the local ethics committee, Regione Calabria Comitato Etico Sezione Area Centro (protocol registry n. 116 of May 14, 2015). Written informed consent was obtained from all individual participants included in the study.

\section{Statistical analysis}

Each quantitative trait was analyzed for distribution using the Shapiro-Wilk normality test and, when required, it was log-transformed. Continuous variables are expressed as median and interquartile range (IQR), and categorical data as number and percentage of the total. Comparison among two groups was performed with the non-parametric Mann-Whitney for continuous variables between two groups and with the 2-tailed Fisher exact test for proportions. Linear regression analysis was employed to examine the quantitative variables that were independently associated with osteocalcin levels, adding appropriate covariates. Statistical significance was inferred at a 2-tailed $P$ value $<0.05$. Analyses were performed using the SPSS 20.0 software (SPSS Inc., Chicago, IL, USA).

\section{Results}

\section{Palmitate causes insulin resistance in MG-63 cells}

As an insulin-sensitive cell type [21], MG-63 cells were chosen as an appropriate in vitro osteoblastic-like model to study the role of insulin in osteoblasts. Palmitate, a typical saturated free fatty acid was used to induce insulin resistance in these cells, thereby reducing insulin signaling. As shown in Fig. 1a, treatment of MG-63 cells with $10 \mathrm{nM}$ insulin induced AKT phosphorylation, whereas this induction was prevented in cells pre-treated with $200 \mu \mathrm{M}$ palmitate. Likewise, in parallel experiments, while insulin induced IRS-1 phosphorylation in untreated insulin sensitive MG-63 cells, insulin stimulation of IRS-1 phosphorylation was impaired in the presence of palmitate (Fig. 1b).

\section{Insulin resistance and high glucose reduce osteocalcin gene expression in MG-63 cells}

Insulin resistance in MG-63 cells was induced first by treating cells with $200 \mu \mathrm{M}$ palmitate for up to $48 \mathrm{~h}$. Thus, to understand the effect of insulin resistance on osteocalcin gene expression, time-course experiments were performed in normal and insulin resistant MG-63 osteoblasts, either untreated or treated with $10 \mathrm{nM}$ insulin for different exposure times (15 min; 6, 24, $48 \mathrm{~h}$ ). As shown in Fig. 2a, osteocalcin mRNA expression was stimulated by insulin, reaching its maximum at $24 \mathrm{~h}$ post-treatment and declining thereafter in insulin-sensitive MG-63 cells. In contrast, no variations in osteocalcin mRNA expression were observed in palmitate pre-treated, insulin resistant cells, as well as in insulin-unstimulated control cells. These findings, while confirming the role of insulin in the regulation of osteocalcin gene expression in this cell line, clearly demostrate that, under conditions of insulin resistance, osteocalcin gene expression is precluded.

An inverse correlation between osteocalcin and hyperglycemia has been reported in clinical studies [22, 23]. Therefore, we studied the effects of low $(2 \mathrm{mM})$ and high (25 mM) glucose concentrations on osteocalcin gene expression in vitro, in MG-63 cells that were grown in standard and modified glucose containing medium for 24 and $96 \mathrm{~h}$ periods. While no significant difference was observed in osteocalcin gene expression after the 24-hr incubation period in low and high glucose, a significant increase in osteocalcin mRNA levels was observed in cells treated with $2 \mathrm{mM}$ glucose after the 96-h experimental 
Fig. 1 Palmitate reduces insulin signaling in MG-63 osteoblastlike cells. a Representative western blots (WB) of phosphorylated (pAKT) and unphosphorylated AKT in MG63 control cells (-), and in cells stimulated with insulin $(+)$ for $15 \mathrm{~min}$, either in the absence or presence of $200 \mu \mathrm{M}$ palmitate for $48 \mathrm{~h}$. b Representative WBs of phosphorylated (pIRS-1) and unphosphorylated IRS-1 in MG63 cells treated as in a. $\beta$ tubulin, control of protein loading. Densitometric analyses of three independent blots (mean \pm SEM) from three independent experiments are shown in each condition. $* P<$ 0.05 vs. insulin-untreated control cells a
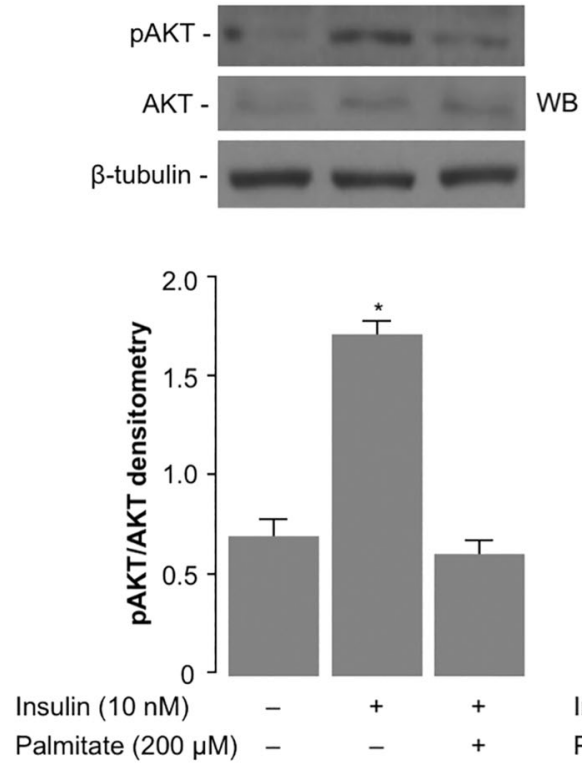

b
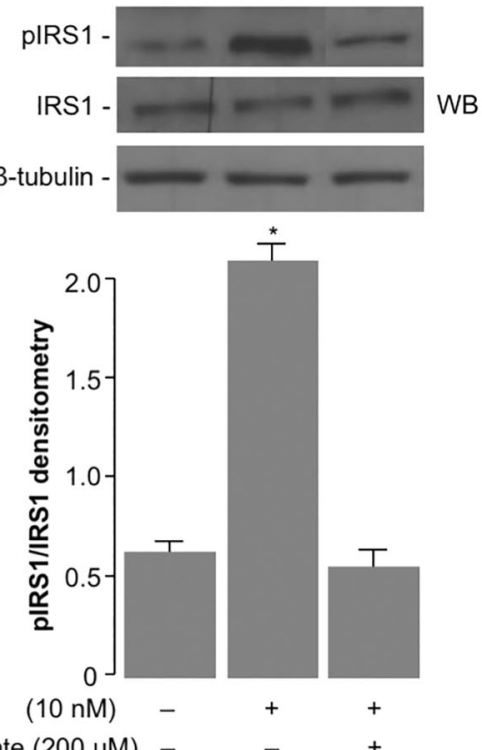

a

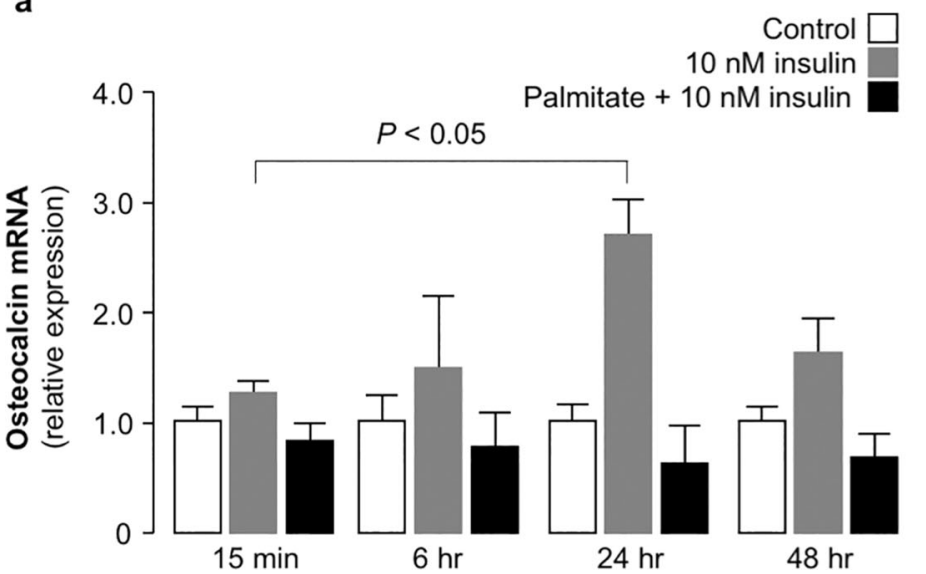

b

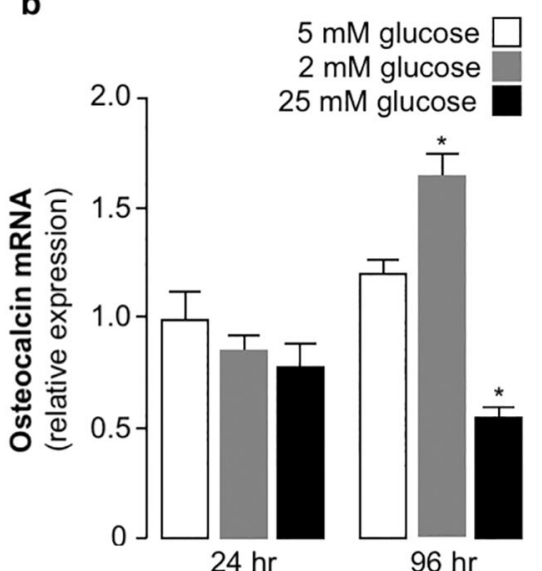

Fig. 2 Insulin resistance and high glucose prevent osteocalcin gene expression in MG-63 cells. a qRT-PCR analysis of the expression of osteocalcin gene in untreated (Control), or insulin-treated MG-63 cells for up to $48 \mathrm{~h}$, with and without pre-treatment with $200 \mu \mathrm{M}$ palmitate. In all qRT-PCR experiments, data shown represent means \pm SEM of three independent experiments, each in triplicate. b qRT-PCR analysis of the expression of osteocalcin gene in MG-63 cells grown in different concentrations of glucose containing medium for 24 and $96 \mathrm{~h}$ periods. Results are means \pm SEM of three independent experiments, each in triplicate. ${ }^{*} P<0.05$ vs. control $(5 \mathrm{mM}$ glucose at $24 \mathrm{~h})$ period, together with a reduction of osteocalcin mRNA in cells treated with $25 \mathrm{mM}$ glucose during the same 96-h time period (Fig. 2b), recapitulating the situation found in previous clinical studies, in which glycemia inversely correlated with circulating osteocalcin [22, 23].

\section{Glucose regulates osteocalcin gene expression by acting in trans at the transcriptional level}

Because of the effect of glucose on osteocalcin gene expression in MG-63 cells, we then hypothesized that high glucose could be acting, at least in part, by blocking the human osteocalcin gene promoter. Methods of bioinformatic analysis were applied to scan the entire osteocalcin gene promoter [24], in order to identify putative sites for glucose response. A site at 404 bp before the ATG starting codon was identified, whose sequence, CACGgggctgacagtag, was recognized by the carbohydrate response element binding protein, ChREBP, thereby suggesting a possible molecular link between glucose and the osteocalcin gene. Therefore, gene reporter experiments were performed to verify the activity of glucose on the promoter region of the osteocalcin gene. To this end, a plasmid containing the human osteocalcin promoter (pOC) cloned 


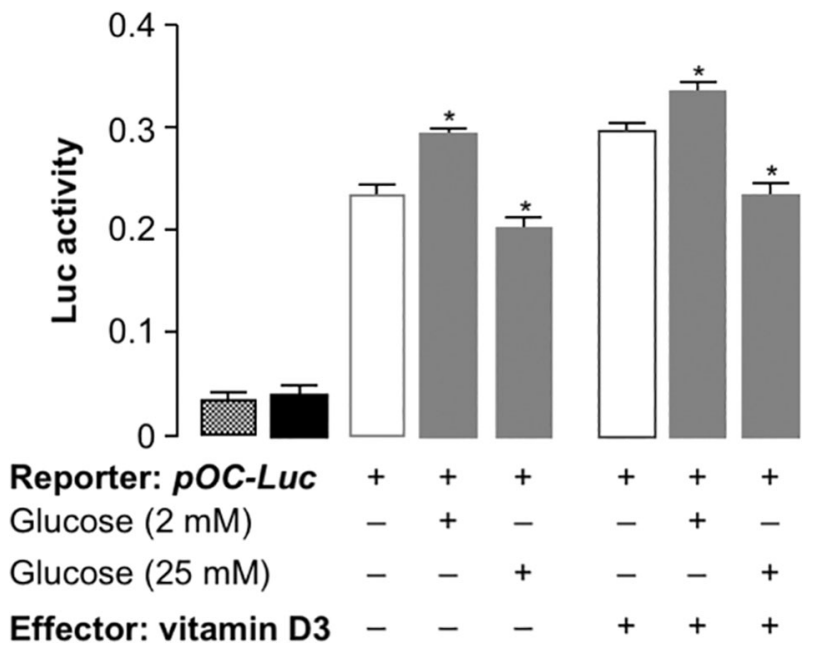

Fig. 3 Glucose regulates osteocalcin gene transcription. MG-63 cells grown in normal glucose concentration $(5 \mathrm{mM})$, were transfected with pOC-Luc and incubated with low $(2 \mathrm{mM})$ or high $(25 \mathrm{mM})$ glucose concentration, either in the presence or absence of $1 \mathrm{nM} 1 \alpha, 25(\mathrm{OH})$ $2 \mathrm{D} 3$, and Luc activity was measured $48 \mathrm{~h}$ later. Data are means \pm SEM for five separate experiments. Luc activity from the reporter plasmid was normalized by the renilla luc activity produced from control vector ( $\mathrm{p} \Delta$ OC-Luc) cotransfected as an internal control. Pattern bar, mock (no DNA); black bar, $\mathrm{p} \Delta \mathrm{OC}$-Luc (without the osteocalcin promoter). $* P<0.05$ vs. $5 \mathrm{mM}$ glucose (white bar, in each condition)

upstream of the luciferase (Luc) reporter gene, pOC-Luc [15], was transfected into MG-63 cells, and Luc activity was measured after $48 \mathrm{~h}$ from transfection in cells treated with either 2 or $25 \mathrm{mM}$ glucose. As shown in reporter gene assays, pOC-Luc activity was moderately, but significantly reduced in MG-63 cells treated with $25 \mathrm{mM}$ glucose, as compared to cells treated with $2 \mathrm{mM}$ glucose (Fig. 3). The addition to cultured osteoblasts of $1 \mathrm{nM} 1 \alpha, 25$-dihydroxyvitamin D3, a factor known to stimulate the osteocalcin gene promoter [25], slightly increased Luc activity at both glucose concentrations, further supporting the notion that a relationship indeed exists between glucose concentration and osteocalcin gene transcription. In parallel experiments using the same pOC-Luc construct in human embryonic HEK-293 cells (not shown), Luc activity was not modulated by either glucose concentrations or vitamin $\mathrm{D}$, and this was most likely due to the cell specificity of this promoter.

\section{Glucose and insulin resistance negatively affect osteoblastic MG-63 cell differentiation while inhibiting osteocalcin gene expression}

To verify whether glucose could influence osteoblastic differentiation, ARS staining assays [17] were performed in MG-63 cells. This assay measures the osteogenic differentiation in terms of colorimetric intensity. Briefly, during the osteogenic differentiation of osteoblasts, $\mathrm{Ca}^{2+}$ ions are deposited in the extracellular matrix, where they a
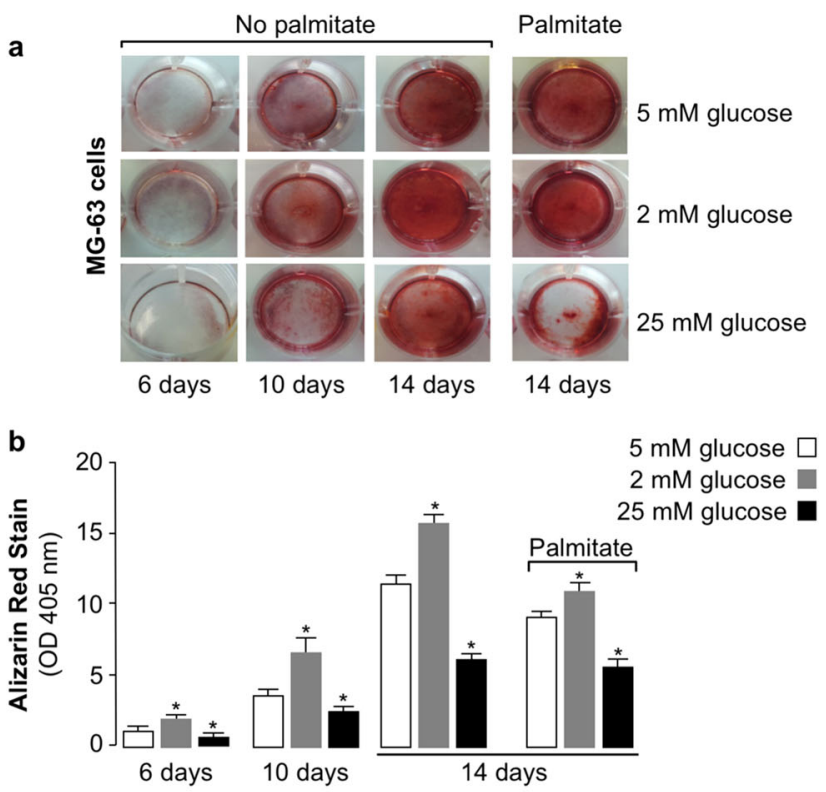

C

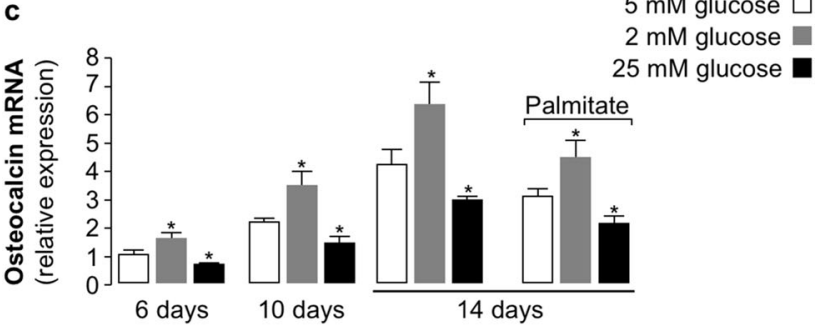

Fig. 4 Osteogenic differentiation in MG-63 cells is reduced by glucose and insulin resistance. Alizarin Red S staining (ARS) assay for calcium deposition was carried out at 6,10 , and 14 days in MG-63 cells cultured with osteogenic differentiation medium in the presence of standard $(5 \mathrm{mM})$, low $(2 \mathrm{mM})$, or high $(25 \mathrm{mM})$ glucose concentrations, with or without $200 \mu \mathrm{M}$ palmitate pretreatment for $48 \mathrm{~h}$. a The extent of mineralization nodule formation is shown in each condition after ARS. b Semi-quantitative analysis of ARS particles. Extracted solution was measured by the absorbance at $405 \mathrm{~nm}$. Data are from six experiments. $* P<0.05$ vs. control ( $5 \mathrm{mM}$ glucose, in each condition). $\mathbf{c}$ Results from qRT-PCR of the osteocalcin mRNA in MG63 cells during osteogenic cell differentiation. Cells were grown in osteogenic differentiation medium in the presence of standard $(5 \mathrm{mM})$, low $(2 \mathrm{mM})$, or high $(25 \mathrm{mM})$ glucose concentration for 6-14 days. The effect of palmitate-induced insulin resistance on osteocalcin mRNA is shown in cells during the 14-days of culture only. Data are means \pm SEM for six experiments. $* P<0.05$ vs. control (white bar, in each group)

subsequently crystallize. Greater is the osteogenic differentiation, more abundant are the calcium crystals in the matrix that could be bound by dye molecules. Treatment of MG-63 cells with 2, 5 and $25 \mathrm{mM}$ glucose were performed at different exposure times up to 14 days. Also, to verify the influence of insulin resistance in osteogenic differentiation, pre-treatment of cells with $200 \mu \mathrm{M}$ palmitate was performed in parallel experiments, under the same reaction conditions. As shown in Figs. 4a, b, in insulin-sensitive cells, osteogenic differentiation was time-dependent and inversely 
affected by glucose concentration. In fact, while $2 \mathrm{mM}$ glucose increased MG-63 cell differentiation when compared with $5 \mathrm{mM}$ standard glucose concentration, $25 \mathrm{mM}$ glucose reduced cell differentiation, and this occurred at each time point tested. In experiments with palmitateinduced insulin resistant cells, osteogenic differentiation was considerably reduced with respect to insulin-sensitive cells, and this reduction was observed at each glucose concentration.

To see whether glucose or insulin resistance played a role in osteocalcin expression in MG-63 cells during osteogenic cell differentiation, we performed time-course experiments in which MG-63 cells, either untreated or pre-treated with palmitate to induce in vitro insulin resistance, were incubated with low $(2 \mathrm{mM})$ or high $(25 \mathrm{mM})$ glucose for 6-14 days. As shown in Fig. 4c, MG-63 osteoblasts progressively increased their expression of osteocalcin mRNA during osteogenic differentiation of cells grown in $5 \mathrm{mM}$ standard glucose concentration. Instead, higher and lower amounts of osteocalcin mRNA were detected in MG-63 cells exposed to low and high glucose concentration, respectively, and this is consistent with the above data indicating that osteocalcin expression inversely correlates with glucose concentration in MG-63 cultured cells. Once again, in palmitate-treated insulin resistant cells, osteocalcin mRNA levels were lower, as compared to untreated insulin sensitive MG-63 cells, after the same 14-days

Fig. 5 Insulin expression and secretion are affected by conditioned medium $(\mathrm{CM})$ from differentiated MG-63 cells. a INS- 1 cells were incubated with normal culture medium $(3 \mathrm{mM}$ glucose, control) or medium containing $15 \mathrm{mM}$ glucose. 100 or $300 \mu \mathrm{L}$ of $\mathrm{CM}$ from insulin sensitive or insulin resistant (200 $\mu$ M palmitate) MG-63 cells were added to INS-1 cultured cells for $2 \mathrm{~h}$, and qRT-PCR of the insulin cDNA obtained from INS- 1 cells in each indicated condition was performed. b A rat insulin ELISA kit was used to quantify insulin secretion into the culture medium of INS-1 cells treated as in a. Data in a and $\mathbf{b}$ are means \pm SEM for six experiments. $* P<0.05$ vs. control (white bar, in each condition; $* * P<0.05$ vs. $\mathrm{CM}$ $100 \mu \mathrm{L}$ and $300 \mu \mathrm{L}$, respectively). A representative WB of osteocalcin $(\mathrm{OCN})$ protein abundance in $\mathrm{CM}$ from insulin sensitive and insulin resistant MG-63 cells is shown in the inset differentiation period, thereby indicating that both high glucose and insulin resistance negatively affect ostecalcin expression during osteogenic differentiation.

\section{Conditioned medium from differentiated MG-63 cells negatively affects insulin gene expression and secretion in INS-1 cells}

To better understand whether a loop existed between bone and pancreatic $\beta$-cells, we next treated rat INS- 1 cells, a cell line that exhibits glucose-stimulated insulin secretion, with conditioned medium from differentiated MG-63 cells, either untreated or pre-treated with palmitate, in the absence or presence of insulin. Under these conditions, osteocalcin protein abundance increased in conditioned medium from insulin stimulated cells but not in cells pre-treated with palmitate (Fig. 5, inset). Treatment of INS-1 cells with increasing amounts $(100$ and $300 \mu \mathrm{L})$ of conditioned medium from differentiated insulin-sensitive MG-63 cells showed a dose-dependent increase in the levels of insulin mRNA, as compared with glucose-alone treated cells, whereas no rise on insulin mRNA expression was observed in INS-1 cells treated with increasing amounts of conditioned medium from palmitate-treated, insulin-resistant MG-63 cells (Fig. 5a). Additional experiments were carried out to investigate whether, coherently with insulin gene expression, conditioned medium from MG-63 cells could

\author{
in the inset
}

a

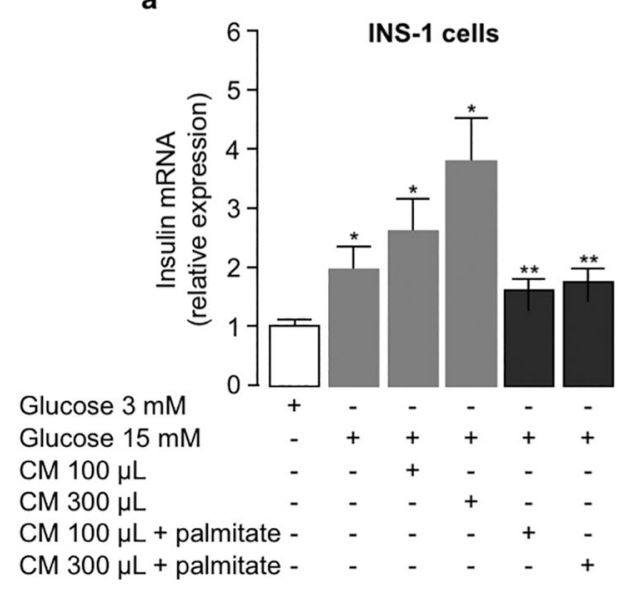

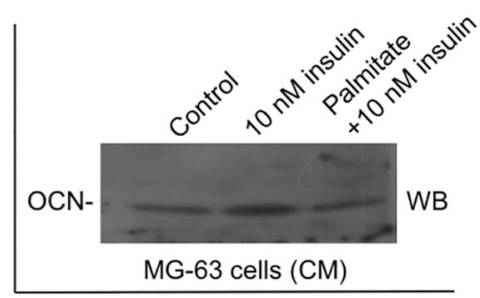

b

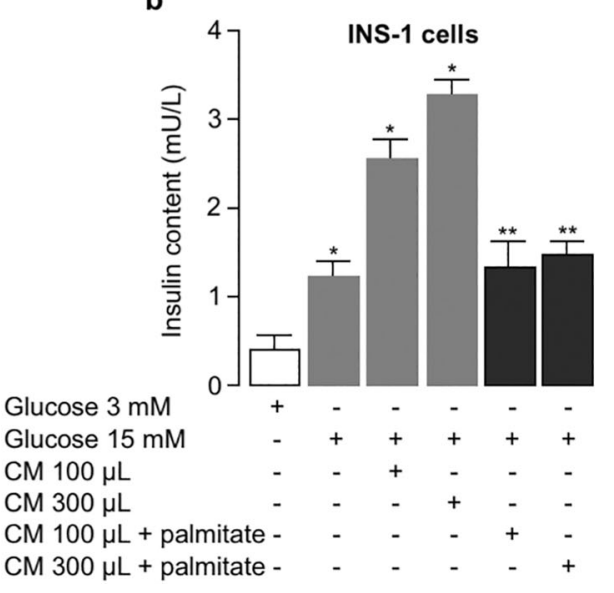


also affect insulin secretion in INS-1 cells. To this end, quantitative measurements of insulin in the culture medium of INS-1 cells were achieved by ELISA. As shown in Fig. $5 \mathrm{~b}$, the results obtained from these assays paralleled those of the expression studies previously mentioned, reinforcing the concept that insulin sensitivity/insulin resistance in bone cells can influence $\beta$-cell insulin production and secretion.

Although we cannot exclude the influence of residual lipotoxicity of palmitate on the impairment of glucosestimulated insulin production, these results are compatible with the view that osteocalcin may have a direct role in insulin gene expression and this effect is negatively affected by resistance of differentiated MG-63 cells to insulin.

\section{Serum osteocalcin levels inversely correlate with HbA1c}

To validate our in vitro findings in a clinical setting, we finally performed a study in humans to see whether a correlation existed between chronic hyperglycemia and/or insulin resistance, and circulating osteocalcin levels. Initially, by employing the non-parametric Mann-Whitney test, we observed that serum osteocalcin levels were markedly lower in diabetic patients $(14.7 \mathrm{ng} / \mathrm{mL}, 12.6-18.3)$ than in control subjects $(20.6 \mathrm{ng} / \mathrm{mL}, \quad 16.9-24.9) \quad(P<0.001)$. Similarly, when we considered the glycemic cut-off value of $100 \mathrm{mg} / \mathrm{dL}$, serum osteocalcin was lower in subjects who had a blood glucose value $\geq 100 \mathrm{mg} / \mathrm{dL} \quad(16.8 \mathrm{ng} / \mathrm{mL}$, 13.9-21.2), and higher in subjects with blood glucose $\leq$ $100 \mathrm{mg} / \mathrm{dL}(20.5 \mathrm{ng} / \mathrm{mL}, 17.5-24.1)(P=0.045)$. To better understand the association of osteocalcin with glycometabolic parameters, we performed multiple linear regression analyses, including age, sex, and BMI as covariates. In detail, when the entire enrolled population was considered, serum osteocalcin was negatively associated with HbA1c levels $(P=0.001)$, while no association was observed with neither fasting plasma glucose $(P=0.089)$ or HOMA-IR $(P=0.251)$ (Table 2$)$. Association of osteocalcin with $\mathrm{HbA} 1 \mathrm{c}$ was confirmed in a same multiple linear regression analysis including only the control population (Table 2), whereas, no association was detected when only patients with DM2 were considered (Table 2). Also, no difference was observed when the enrolled population was distinguished on the basis of either HOMA-IR $<1.6$ ( $P=$ $0.114)$ or HOMA-IR $>2.5(P=0.279)$. Therefore, altogether, these findings indicate that serum osteocalcin and glucose levels are inversely correlated, while no correlation appears between insulin resistance and osteocalcin.

\section{Discussion}

Until recently, bone has been considered solely as a structural tissue, without metabolic significance. The hypothesis
Table 2 Relationship between osteocalcin levels and glucose parameters in enrolled population, control population, and DM2 population

\begin{tabular}{|c|c|c|c|c|}
\hline & B & beta & $t$ & $P$-value \\
\hline \multicolumn{5}{|c|}{ Enrolled population } \\
\hline FPG & -0.043 & -0.236 & -1732 & 0.089 \\
\hline $\mathrm{HbAlc}$ & -2.318 & -0.432 & -3.390 & 0.001 \\
\hline HOMA-IR & -0.137 & -0.153 & -1.161 & 0.251 \\
\hline \multicolumn{5}{|c|}{ Control population } \\
\hline FPG & 0.096 & 0.166 & 0.984 & 0.332 \\
\hline $\mathrm{HbA} 1 \mathrm{c}$ & -7.680 & -0.338 & -2.188 & 0.035 \\
\hline HOMA-IR & -0.003 & -0.001 & -1.161 & 0.994 \\
\hline \multicolumn{5}{|c|}{ DM2 population } \\
\hline FPG & -0.021 & -0.158 & -0.663 & 0.517 \\
\hline $\mathrm{HbA1c}$ & -4.874 & -0.134 & -0.622 & 0.543 \\
\hline HOMA-IR & -0.018 & -0.037 & -1.161 & 0.866 \\
\hline
\end{tabular}

Linear regression analysis was used for assessing the effect of the osteocalcin on fasting plasma glucose (FPG), HbAlc, and HOMA-IR, adding age, gender, and BMI as covariates

of a link between bone and energy metabolism has been first based on the observation that obesity protects from osteoporosis [26], thus suggesting a common hormonal regulation of bone mass and energy metabolism. Testing this hypothesis allowed the identification of leptin, an adipokine produced by adipose tissue, as a point of convergence between bone and energy metabolism [27]. Additional investigation on this topic led authors to discover that the bone-specific hormone, osteocalcin, while playing important roles in bone remodeling, also contributes to glucose metabolism by affecting both insulin secretion and insulin sensitivity [28]. Furthermore, the link between bone and glucose metabolism is supported by clinical observations indicating that patients with diabetes show an increased risk of fractures because of osteopenia or osteoporosis [29-32]. Similar observations also resulted from studies with animal models [33, 34].

However, although the above-mentioned information, up to now, few in vitro models have been developed to better understand, at the molecular level, how insulin and glucose can regulate osteocalcin. In this study, we used MG-63 human osteoblast-like cells for studying osteocalcin gene expression, osteogenic differentiation, and osteblastmediated insulin secretion. We first set up an in vitro model of insulin-resistant osteoblasts by treating MG-63 cells with palmitate, a typical saturated free fatty acid. We demonstrated in vitro, in MG-63 cells, that insulin resistance, as well as high glucose concentration $(25 \mathrm{mM})$ in the culture medium, inhibited osteocalcin gene expression. The human osteocalcin promoter has been previously studied $[15,25]$ and its responsiveness to several agents, including glucocorticoids, vitamin $\mathrm{D}$, and cytokines, such 
as TGF- $\beta$, as well as transcription factors has been reported [25, 35-37]. Using reporter gene analysis, we have shown, for the first time, that glucose decreased osteocalcin gene expression at the level of gene transcription, and this may be due to the glucose-mediated effects on the putative ChREBP consensus site in the osteocalcin promoter region, as evidenced by bioinformatic analysis.

Based on the assumption that a physiological interaction occurs among bone and pancreas, in relation to the regulation of energy metabolism, and that a positive loop exists between osteocalcin and insulin, co-culture experiments in which osteocalcin-producing COS cells were able to induce insulin secretion from pancreatic islets, but not other hormones, had proved the endocrine activity of osteocalcin in vitro [28]. This aspect was clarified by cell biology experiments, in which co-cultures of pancreatic islets and wild-type osteoblasts stimulated insulin secretion, whereas osteocalcin-/- osteoblasts did not [28]. In our study, conditioned medium from insulin sensitive and insulin resistant MG-63 osteoblasts differently affected insulin gene expression and secretion in INS-1 cultured $\beta$-cells. Although these findings do not prove that differences in insulin secretion unequivocally reflect differences in the release of osteocalcin from insulin-sensitive vs. insulinresistant osteoblasts, they do provide additional support for a functional relationship between osteocalcin and insulin, with the understanding that we cannot exclude that other MG-63 secreted biomolecules may play a role in this endocrine activity.

Insulin resistance and chronic hyperglycemia are the main metabolic perturbations in patients with type 2 diabetes. In these patients, clinical evidence exists that bone disorders as osteoporosis and bone fractures are more frequent than in other individuals [29-32]. It has been postulated that the reduced levels of osteocalcin may have a role in this context [22, 23]. Results in animal models have encouraged a series of clinical studies, which tried to associate circulating osteocalcin levels with clinical and/or biochemical parameters in different cohorts of patients [38-42]. Although many findings indicate that an inverse correlation exists between total or undercarboxylated osteocalcin and glucose levels, the debate is still open. Since our findings show that insulin resistance and high glucose reduce osteocalcin expression in vitro, we investigated how insulin resistance and/or chronic hyperglycemia affected serum osteocalcin levels in patients. As we found a significant correlation between poor glycemic control and reduced levels of serum osteocalcin, it appears plausible to assume that chronic hyperglycemia (rather than insulin resistance) might have a preminent role in this reduction. Our observation, in this context, well supports previous studies, in which the association of hyperglycemia with low serum osteocalcin levels has been reported [22, 23,
43]. As the number of patients included in our study was relatively low, the significance of this finding deserves further investigation in a larger number of patients. In this regard, the lack of correlation between insulin resistance and osteocalcin levels in our data set may depend on the small sample size of the study, since a correlation between insulin resistance and osteocalcin in patients with insulin resistant syndromes has been observed only in larger cohort studies [44-47]. Thus, future investigation is necessary to establish whether osteocalcin may represent a novel therapeutic target in conditions that range from osteopenia or osteoporosis to insulin resistance and overt diabetes.

\section{Compliance with ethical standards}

Conflict of interest The authors declare that they have no competing interests.

Ethical approval All procedures performed in studies involving human participants were in accordance with the ethical standards of the institutional and/or national research committee and with the 1964 Helsinki declaration and its later amendments or comparable ethical standards.

Informed consent Informed consent was obtained from all individual participants included in the study.

Open Access This article is distributed under the terms of the Creative Commons Attribution 4.0 International License (http://crea tivecommons.org/licenses/by/4.0/), which permits unrestricted use, distribution, and reproduction in any medium, provided you give appropriate credit to the original author(s) and the source, provide a link to the Creative Commons license, and indicate if changes were made.

\section{References}

1. A.R. Saltiel, C.R. Kahn, Insulin signalling and the regulation of glucose and lipid metabolism. Nature. 414, 799-806 (2001)

2. M. Ferron, J. Wei, T. Yoshizawa, A. Del Fattore, R.A. DePinho, A. Teti, P. Ducy, G. Karsenty, Insulin signaling in osteoblasts integrates bone remodeling and energy metabolism. Cell 142, 296-308 (2010)

3. S. Harada, G. Rodan, Control of osteoblast function and regulation of bone mass. Nature. 423, 349-355 (2003)

4. M.F. Faienza, V. Luce, A. Ventura, G. Colaianni, S. Colucci, L. Cavallo, M. Grano, G. Brunetti, Skeleton and glucose metabolism: a bone-pancreas loop. Int. J. Endocrinol. 2015:758148 (2015) https://doi.org/10.1155/2015/758148

5. K.W. Ng, T.J. Martin, New functions for old hormones: Bone as an endocrine organ. Mol. Cell. Endocrinol. 310, 1-2 (2009)

6. G. Lombardi, S. Perego, L. Luzi, G. Banfi, A four-season molecule: osteocalcin. Updates in its physiological roles. Endocrine 48, 394-404 (2015)

7. M. Murshed, T. Schinke, M.D. McKee, G. Karsenty, Extracellular matrix mineralization is regulated locally; different roles of two gla-containing proteins. J. Cell. Biol. 165, 625-630 (2004)

8. P. Ducy, C. Desbois, B. Boyce, G. Pinero, B. Story, C. Dunstan, E. Smith, J. Bonadio, S. Goldstein, C. Gundberg, A. Bradley, G. 
Karsenty, Increased bone formation in osteocalcin-deficient mice. Nature. 382, 448-452 (1996)

9. A. Mizokami, T. Kawakubo-Yasukochi, M. Hirata, Osteocalcin and its endocrine functions. Biochem. Pharmacol. 132, 1-8 (2017)

10. I. Kanazawa, Osteocalcin as a hormone regulating glucose metabolism. World J. Diabetes 6, 1345-1354 (2015)

11. J. Wei, M. Ferron, C.J. Clarke, Y.A. Hannun, H. Jiang, W.S. Blaner, G. Karsenty, Bone-specific insulin resistance disrupts whole-body glucose homeostasis via decreased osteocalcin activation. J. Clin. Invest. 124, 1-13 (2014)

12. M.R. Rubin, Bone cells and bone turnover in diabetes mellitus. Curr. Osteoporos. Rep. 13, 186-191 (2015)

13. B. Arcidiacono, S. Iiritano, E. Chiefari, F.S. Brunetti, G. Gu, D.P. Foti, A. Brunetti, Cooperation between HMGA1, PDX-1, and MafA is essential for glucose-induced insulin transcription in pancreatic beta cells. Front. Endocrinol. 5, 237 (2015). https:// doi.org/10.3389/fendo.2014.00237

14. D. Foti, E. Chiefari, M. Fedele, R. Iuliano, L. Brunetti, F. Paonessa, G. Manfioletti, F. Barbetti, A. Brunetti, C.M. Croce, A. Fusco, A. Brunetti, Lack of the architectural factor HMGA1 causes insulin resistance and diabetes in humans and mice. Nat. Med. 11, 765-773 (2005)

15. T. Nakanishi, K. Kokubun, H. Oda, M. Aoki, A. Soma, M. Taniguchi, Y. Kazuki, M. Oshimura, K. Sato, Bioluminescence imaging of bone formation using hairless osteocalcin-luciferase transgenic mice. Bone 51, 369-375 (2012)

16. S. Iiritano, E. Chiefari, V. Ventura, B. Arcidiacono, K. Possidente, A. Nocera, M.T. Nevolo, M. Fedele, A. Greco, M. Greco, G. Brunetti, A. Fusco, D. Foti, A. Brunetti, The HMGA1-IGF-I/ IGFBP system: a novel pathway for modulating glucose uptake. Mol. Endocrinol. 26, 1578-1589 (2012)

17. C.A. Gregory, W.G. Gunn, A. Peister, D.J. Prockop, An alizarin red-based assay of mineralization by adherent cells in culture: comparison with cetylpyridinium chloride extraction. Anal. Biochem. 329, 77-84 (2004)

18. V. Costa, D. Foti, F. Paonessa, E. Chiefari, L. Palaia, G. Brunetti, E. Gulletta, A. Fusco, A. Brunetti, The insulin receptor: a new anticancer target for peroxisome proliferator-activated receptor- $\gamma$ $(\mathrm{PPAR} \gamma)$ and thiazolidinedione-PPAR $\gamma$ agonists. Endocr. Relat. Cancer. 15, 325-335 (2008)

19. A. Bianconcini, A. Lupo, S. Capone, L. Quadro, M. Monti, D. Zurlo, A. Fucci, L. Sabatino, A. Brunetti, E. Chiefari, M.E. Gottesman, W.S. Blaner, V. Colantuoni, Transcriptional activity of the murine retinol-binding protein gene is regulated by a multiprotein complex containing HMGA1, p54nrb/NonO, proteinassociated splicing factor (PSF) and steroidogenic factor 1 (SF1)/ liver receptor homologue 1 (LRH-1). Int. J. Biochem. Cell. Biol. 41, 2189-2203 (2009)

20. C.R. Pullinger, I.D. Goldfine, S. Tanyolac, I. Movsesyan, M. Faynboym, V. Durlach, E. Chiefari, D.P. Foti, P.H. Frost, M.J. Malloy, A. Brunetti, J.P. Kane, Evidence that an HMGA1 gene variant associates with type 2 diabetes, body mass index, and high-density lipoprotein cholesterol in a Hispanic-American population. Metab. Syndr. Relat. Disord. 12, 25-30 (2014)

21. M. Cifuentes, M.A. García, P.M. Arrabal, F. Martinez, M.J. Yaňez, N. Jara, B. Weil, D. Domínguez, R.A. Medina, F. Nualart, Insulin regulates GLUT1-mediated glucose transport in MG-63 human osteosarcoma cells. J. Cell. Physiol. 226, 1425-1432 (2011)

22. P.D. Sarkar, A.B. Choudhury, Relationships between serum osteocalcin levels versus blood glucose, insulin resistance and markers of systemic inflammation in central Indian type 2 diabetic patients. Eur. Rev. Med. Pharmacol. Sci. 17, 1631-1635 (2013)

23. Y.C. Hwang, I.K. Jeong, K.J. Ahn, H.Y. Chung, Circulating osteocalcin level is associated with improved glucose tolerance, insulin secretion and sensitivity independent of the plasma adiponectin level. Osteoporos. Int. 23, 1337-1342 (2012)

24. S. Messineo, A.E. Laria, B. Arcidiacono, E. Chiefari, R.M. Luque Huertas, D.P. Foti, A. Brunetti, Cooperation between HMGA1 and HIF-1 contributes to hypoxia-induced VEGF and visfatin gene expression in 3T3-L1 adipocytes. Front. Endocrinol. 7, 73 (2016). https://doi.org/10.3389/fendo.2016.00073

25. T. Nakanishi, R. Saito, M. Taniguchi, H. Oda, A. Soma, M. Yasunaga, M. Yamane, K. Sato, In Vivo determination of vitamin D function using transgenic mice carrying a human osteocalcin luciferase reporter gene. Biomed. Res. Int. 2013, 895706 (2013). https://doi.org/10.1155/2013/895706

26. P. Ducy, M. Amling, S. Takeda, M. Priemel, A.F. Schilling, F.T. Beil, J. Shen, C. Vinson, J.M. Rueger, G. Karsenty, Leptin inhibits bone formation through a hypothalamic relay: a central control of bone mass. Cell 100, 197-207 (2000)

27. F.J.A. de Paula, C.J. Rosen, Bone remodeling and energy metabolism: new perpectives. Bone Res. 1, 72-84 (2013)

28. M.L. Zoch, T.L. Clemens, R.C. Riddle, New insights into the biology of osteocalcin. Bone 82, 42-49 (2016)

29. M. Janghorbani, D. Feskanich, W.C. Willett, F. Hu, Prospective study of diabetes and risk of hip fracture: The nurses' health study. Diabetes Care 29, 1573-1578 (2006)

30. K.K. Nicodemus, A.R. Folsom, Type 1 and type 2 diabetes and Incident hip fractures in postmenopausal women. Diabetes Care 24, 1192-1197 (2001)

31. J. Starup-Linde, M. Frost, P. Vestergaard, B. Abrahamsen, Epidemiology of fractures in diabetes. Calcif. Tissue Int. 100, 109-121 (2017)

32. S.A.G. Kemink, A.R.M.M. Hermus, L.M.J.W. Swinkels, J.A. Lutterman, A.G.H. Smals, Osteopenia in insulin-dependent diabetes mellitus: prevalence and aspects of pathophysiology. J. Endocrinol. Invest. 23, 295-303 (2000)

33. J. Verhaeghe, W.J. Visser, T.A. Einhorn, R. Bouillon, Osteoporosis and diabetes: lessons from the diabetic BB rat. Horm. Res. Paediatr. 34, 245-248 (1990)

34. W.G. Goodman, M.T. Hori, Diminished bone formation in experimental diabetes. Relationship to osteoid maturation and mineralization. Diabetes 33, 825-831 (1984)

35. N.A. Sims, C.P. White, K.L. Sunn, G.P. Thomas, M.L. Drummond, N.A. Morrison, J.A. Eisman, E.M. Gardiner, Human and murine osteocalcin gene expression: conserved tissue restricted expression and divergent responses to 1,25-dihydroxyvitamin D3 in vivo. Mol. Endocrinol. 11, 1695-1708 (1997)

36. D.M. Piscopo, E.B. Johansen, R. Derynck, Identification of the GATA factor TRPS1 as a repressor of the osteocalcin promoter. J. Biol. Chem. 284, 31690-31703 (2009)

37. H. Chen, E. Hays, J. Liboon, C. Neely, K. Kolman, N. Chandar, Osteocalcin gene expression is regulated by wild-type p53. Calcif. Tissue Int. 89, 411-418 (2011)

38. Y.C. Hwang, I.K. Jeong, K.J. Ahn, H.Y. Chung, The uncarboxylated form of osteocalcin is associated with improved glucose tolerance and enhanced beta-cell function in middleaged male subjects. Diabetes Metab. Res. Rev. 25, 768-772 (2009)

39. G. Strapazzon, L. De Toni, C. Foresta, Serum undercarboxylated osteocalcin was inversely associated with plasma glucose level and fat mass in type 2 diabetes mellitus. Osteoporos. Int. 22, 1643-1644 (2011)

40. J.M. Kindblom, C. Ohlsson, O. Ljunggren, M.K. Karlsson, A. Tivesten, U. Smith, D. Mellström, Plasma osteocalcin is inversely related to fat mass and plasma glucose in elderly Swedish men. J. Bone Miner. Res. 24, 785-791 (2009)

41. I. Kanazawa, T. Yamaguchi, M. Yamamoto, M. Yamauchi, S. Kurioka, S. Yano, T. Sugimoto, Serum osteocalcin level is associated with glucose metabolism and atherosclerosis parameters in 
type 2 diabetes mellitus. J. Clin. Endocrinol. Metab. 94, 45-49 (2009)

42. T. Neumann, S. Lodes, B. Kästner, S. Franke, M. Klehntopf, T. Lehmann, U.A. Müllere, G. Wolf, A. Sämann, Osteocalcin, adipokines and their associations with glucose metabolism in type 1 diabetes. Bone 82, 50-55 (2016)

43. E. Maddaloni, L. D'Onofrio, A. Lauria, A.R. Maurizi, R. Strollo, A. Palermo, N. Napoli, S. Angeletti, P. Pozzilli, S. Manfrini, Osteocalcin levels are inversely associated with Hbalc and BMI in adult subjects with longstanding type 1 diabetes. J. Endocrinol. Invest. 37, 661-666 (2014)

44. M. Iki, J. Tamaki, Y. Fujita, K. Kouda, A. Yura, E. Kadowaki, Y. Sato, J.S. Moon, K. Tomioka, N. Okamoto, N. Kurumatani, Serum undercarboxylated osteocalcin levels are inversely associated with glycemic status and insulin resistance in an elderly Japanese male population: Fujiwara-kyo osteoporosis risk in men (FORMEN) study. Osteoporos. Int. 23, 761-770 (2012)
45. A. Díaz-López, M. Bulló, M. Juanola-Falgarona, M.A. MartinezGonzález, R. Estruch, M.I. Covas, F. Arós, J. Salas-Salvadó, Reduced serum concentrations of carboxylated and undercarboxylated osteocalcin are associated with risk of developing type 2 diabetes mellitus in a high cardiovascular risk population: a nested case-control study. J. Clin. Endocrinol. Metab. 98, 4524-4531 (2013)

46. V. Schwetz, E. Lerchbaum, N. Schweighofer, N. Hacker, O. Trummer, O. Borel, T.R. Pieber, R. Chapurlat, B. ObermayerPietsch, Osteocalcin levels on oral glucose load in women being investigated for polycystic ovary syndrome. Endocr. Pract. 20, 5-14 (2014)

47. B. Garanty-Bogacka, M. Syrenicz, M. Rać, B. Krupa, G. CzajaBulsa, M. Walczak, E. Sowiňska-Przepiera, A. Syrenicz, Association between serum osteocalcin, adiposity and metabolic risk in obese children and adolescents. Endokrynol. Pol. 64, 346-352 (2013) 